\title{
Influencing factors of seismic signals generated by un-tuned large volume airgun array in a land reservoir
}

\author{
Meng Chen · Wei Yang • Weitao Wang • \\ Baoshan Wang $\cdot$ Hongkui Ge $\cdot$ Li Chen $\cdot$ \\ Yansheng Ding $\cdot$ Jiyan Qiao $\cdot$ Yong Chen
}

Received: 15 December 2013/ Accepted: 19 February 2014/Published online: 25 April 2014

(c) The Seismological Society of China, Institute of Geophysics, China Earthquake Administration and Springer-Verlag Berlin Heidelberg 2014

\begin{abstract}
Un-tuned large volume airgun array in a water reservoir is recently proposed as a new way to generate seismic waves on land. It can be used to explore the earth velocity structure and its temporal variations as well. However, the characteristics of seismic signals (especially far-field signals) from an airgun array in a reservoir and its affecting factors (firing pressure, airgun towing depth, water level of the reservoir, etc.) has not been adequately studied. We analyzed the seismic data collected from field experiments at Binchuan Transmitting Seismic Station in 2011 and 2013 and found that (1) The similarity of seismic signals decrease with distance, which is most likely induced by the decay of signal amplitude and signal to noise ratio (SNR); (2) The amplitudes of far-field airgun signals are almost linearly proportional to the firing pressure; (3) The towing depth of airgun has less effects on the far-field signals; (4) The amplitudes of far-field airgun signals are proportional to the water level of the reservoir.
\end{abstract}

Keywords Airgun - Water reservoir - Excitation parameter $\cdot$ Far-field

M. Chen $(\bowtie) \cdot$ W. Yang $\cdot$ W. Wang $\cdot$ B. Wang $\cdot$ Y. Chen Key Laboratory of Seismic Observation and Geophysical Imaging, Institute of Geophysics, China Earthquake Administration, Beijing 100081, China

e-mail: eamonustc@gmail.com

H. Ge

Unconventional Natural Gas Institute in China University of Petroleum, Beijing 102249, China

L. Chen · Y. Ding · J. Qiao

Institute of Mechanics, Chinese Academy of Sciences, Beijing 100190, China

\section{Introduction}

Airgun arrays are the most frequently used seismic sources in marine petroleum explorations (Vaage et al. 1983). Most of them are tuned airgun arrays (Dragoset 2000). Tuned airgun arrays can provide improved resolution by concentrating primary pulse and canceling bubble oscillations. Tuned large volume airgun arrays can also be used for deep crustal investigations (Matthews and The BIRPS Group 1990; Choukroune 1989; Lutter et al. 1999; Okaya et al. 2002).

Due to their high repeatability, airguns and airgun arrays were also used for the subsurface velocity monitoring. Reasenberg and Aki (1974) used a 40 in. $^{3}$ airgun in a water-filled hole to monitor in situ velocity variations in a granite quarry. Similar experiments were conducted by Liu et al. in 1981 and 1982 (Liu et al. 1983, 1985). The velocity variations associated with solid earth tides were observed in their studies. To monitor velocity changes at deeper depth, Leary and Malin (1982) used a much larger airgun $\left(1,000\right.$ in. $\left.^{3}\right)$ in San Andreas fault zone.

The seismic signals generated by a single airgun or an airgun array may be affected by many factors (e.g., airgun volume, firing pressure, airgun towing depth, water level, water temperature, and water viscosity). Seismic signals and their influencing factors for ocean used airgun array have been intensively studied since the 1960s (Kramer et al. 1968; Giles and Johnston 1973; Nooteboom 1978; Johnston 1980; Vaage et al. 1983; Langhammer and Landro 1993a, b). The empirical relations between these factors and the characteristics of airgun signatures (e.g., the amplitude of primary pulse, the period of bubble pulse and the primary-to-bubble amplitude ratio) have already been drawn. On the theoretical side, the seismic signatures from ocean used airguns and airgun arrays can be calculated numerically based on the free bubble oscillation theory 
(a)

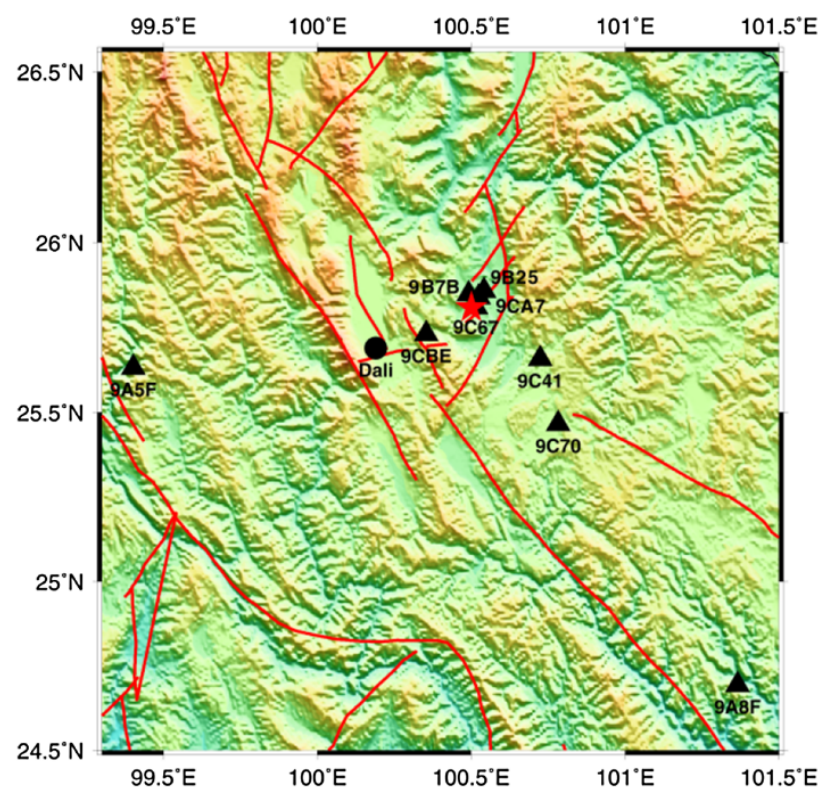

(b)

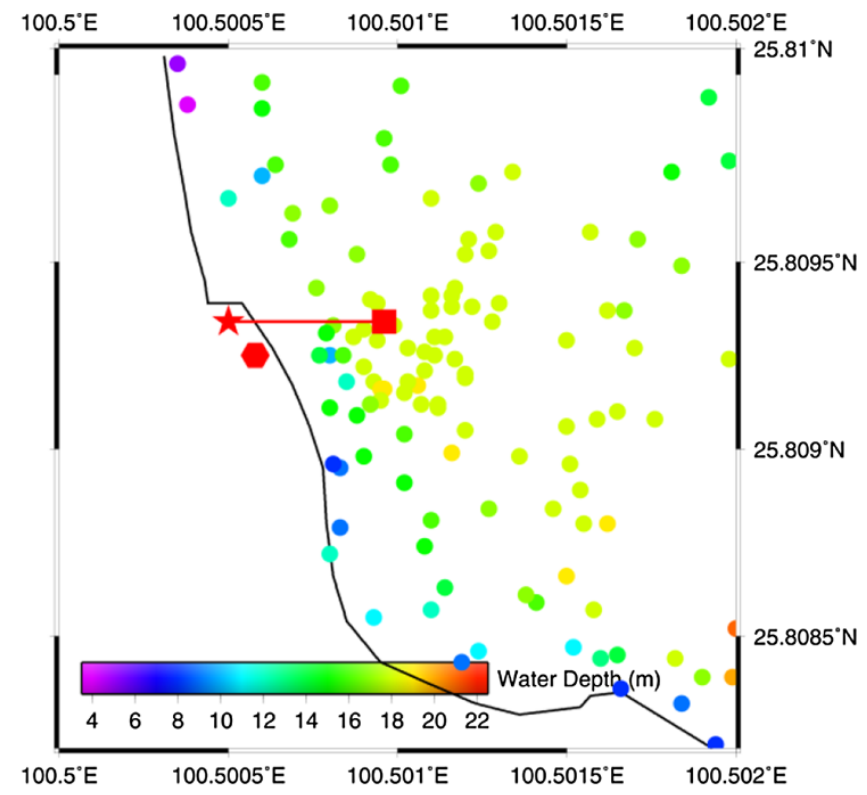

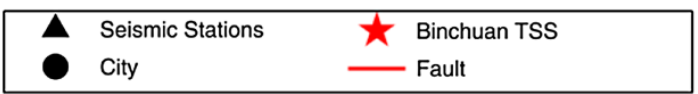

\begin{tabular}{|ll|}
\hline A Tower Crane & Airgun Array \\
Control Room & \\
\hline
\end{tabular}

Fig. 1 a The locations of Binchuan TSS and portable seismic stations used in this study, b The location of the airgun array in Dayindian reservoir and water depth nearby (measured on March 19, 2010)

(Ziolkowski 1970; Schulze-Gattermann 1972; Safar 1976; Cox et al. 2004; Li et al. 2011).

Due to their abundance in low-frequency signals, the untuned airgun arrays were recently used for deep penetration seismic reflection and refraction surveys (Qiu et al. 2007; Chen et al. 2008) and monitoring the crustal evolution (Wang et al. 2012). However, there are very few researches about seismic signals generated by un-tuned airgun array, even fewer researches about seismic signals generated by un-tuned airgun array operated in a water reservoir or lake (Lin et al. 2010).

In this paper, we analyzed the characteristics of seismic signals generated by un-tuned large volume airgun array fired in a water reservoir and their influencing factors (firing pressure, airgun towing depth, and water level of the reservoir) based on field experiments with Binchuan Transmitting Seismic Station (TSS) (Wang et al. 2012). A theoretical model was also proposed to address how these factors may affect the signals. This work is the basis of the future work about subsurface velocity monitoring and also provides some clues in improving the performance of the TSS.

\section{Field experiments with Binchuan TSS}

In order to monitor the crustal velocity variations of the Red River Fault Zone, we built a new type of seismic station called TSS at Dayindian water reservoir in 2011 (Wang et al. 2012). The Dayindian reservoir is located in the west suburbs of Binchuan County, Yunnan Province, China. It is a multi-used irrigation water conservancy project. The total capacity of the reservoir is $40,850,000 \mathrm{~m}^{3}$. The maximum depth of the reservoir is up to $30 \mathrm{~m}$. The seismic source of Binchuan TSS is an un-tuned airgun array composed of 4 Bolt 1500LL airguns. The total volume of the airgun array is $8,000 \mathrm{in}^{3}$. The 4 airguns were installed at the four edges of a $7 \mathrm{~m} \times 7 \mathrm{~m}$ steel frame which was controlled by a tower crane [Fig. 1c in (Wang et al. 2012)].

In April 2011, May 2011, and April 2013 we conducted six experiments in Binchuan TSS. Nine portable seismic stations at different distances are used as receivers (Fig. 1a). Each station is composed of one Guralp CMG-40T sensor and Reftek 130B digitizer with flat amplitude response from 0.5 to $100 \mathrm{~Hz}$. To reduce cultural noise on seismic records, most of the excitations were done from 10 p.m. to next 5 a.m. local time. The water level in the reservoir changes with time due to the precipitation and water consumption. The water level is measured by the reservoir administrator twice a day.

Firing pressures and towing depth of airguns were two factors intensively studied in these experiments. The firing pressures varied from 7 to $15 \mathrm{MPa}$ and towing depth ranged from 7 to $12 \mathrm{~m}$. The detailed excitation parameters used in these experiments are listed in Table 1. 
Table 1 The parameters adopted in experiments

\begin{tabular}{lllllll}
\hline $\begin{array}{l}\text { Experiment } \\
\text { number }\end{array}$ & $\begin{array}{l}\text { Date } \\
\text { (Year.Month.Day) }\end{array}$ & $\begin{array}{l}\text { Total volume } \\
\left.\text { (in. }{ }^{3}\right)\end{array}$ & $\begin{array}{l}\text { Water } \\
\text { level }(\mathrm{m})\end{array}$ & $\begin{array}{l}\text { Gun } \\
\text { depth (m) }\end{array}$ & $\begin{array}{l}\text { Firing } \\
\text { pressure } \\
\text { (MPa) }\end{array}$ & $\begin{array}{l}\text { Number } \\
\text { of shots }\end{array}$ \\
\hline 1 & $2011.4 .14-2011.4 .16$ & 8,000 & 17.7 & 12.0 & 15.0 & 56 \\
2 & $2011.4 .20-2011.4 .22$ & 8,000 & 17.7 & 12.0 & 15.0 & 55 \\
3 & $2011.5 .27-2011.5 .30$ & 8,000 & 12.5 & 10.0 & 15.0 & 17 \\
3 & $2011.5 .27-2011.5 .30$ & 8,000 & 12.5 & 10.0 & 14.0 & 2 \\
3 & $2011.5 .27-2011.5 .30$ & 8,000 & 12.5 & 10.0 & 13.0 & 3 \\
3 & $2011.5 .27-2011.5 .30$ & 8,000 & 12.5 & 10.0 & 12.0 & 2 \\
3 & $2011.5 .27-2011.5 .30$ & 8,000 & 12.5 & 10.0 & 11.0 & 4 \\
3 & $2011.5 .27-2011.5 .30$ & 8,000 & 12.5 & 10.0 & 10.0 & 5 \\
3 & $2011.5 .27-2011.5 .30$ & 8,000 & 12.5 & 10.0 & 9.0 & 2 \\
3 & $2011.5 .27-2011.5 .30$ & 8,000 & 12.5 & 10.0 & 8.0 & 1 \\
3 & $2011.5 .27-2011.5 .30$ & 8,000 & 12.5 & 9.0 & 11.0 & 1 \\
3 & $2011.5 .27-2011.5 .30$ & 8,000 & 12.5 & 8.0 & 11.0 & 1 \\
3 & $2011.5 .27-2011.5 .30$ & 8,000 & 12.5 & 7.0 & 11.0 & 1 \\
4 & 2013.4 .2 & 8,000 & 12.7 & 10.0 & 15.0 & 13 \\
5 & $2013.4 .16-2013.4 .17$ & 8,000 & 12.6 & 10.0 & 15.0 & 13 \\
5 & $2013.4 .16-2013.4 .17$ & 8,000 & 12.5 & 10.0 & 15.0 & 13 \\
6 & 2013.4 .22 & 8,000 & 10.7 & 10.0 & 15.0 & 14 \\
\hline
\end{tabular}

\section{General features of seismic signals}

The seismic signals generated by an airgun source are usually composed of two parts: the primary pressure pulse results from rapid release of high pressure air and bubble oscillation induced bubble pulse (Dragoset 2000; Mayne and Quay 1971). In general, the primary pulse has higher frequency than the bubble pulse. Since, we are utilizing the long propagating low-frequency signals (Chen et al. 2008), we focus on the bubble pulses in this study.

The seismic signals are characterized by their amplitudes, spectral contents, and cross-correlation coefficients (CC). In measuring the signal signatures, we first cut the data according to the shot time, then remove the instrumental response and de-trend the data, and finally band pass filter the data with bandwidths of $2-40$ and $2-10 \mathrm{~Hz}$ for near $(50 \mathrm{~m}, 1.4 \mathrm{~km})$ and far $(\geq 7 \mathrm{~km})$ offsets, respectively. The seismic signals and corresponding spectrogram generated by one shot (under firing pressure: $15 \mathrm{MPa}$, airgun towing depth: $10 \mathrm{~m}$, water level of the reservoir: $12.5 \mathrm{~m}$ ) registered by portable seismic stations are shown in Fig. 2.

From Fig. 2, we can see that the airgun signals propagate at an apparent velocity $\sim 5.6 \mathrm{~km} / \mathrm{s}$, corresponding to the average P-wave velocity in this region (Huang et al. 2012). It also be inferred from Fig. 2 that seismic signal generated from one shot can be traced up to $151 \mathrm{~km}$. The dominant frequency range of airgun signals recorded by the seismometer $50 \mathrm{~m}$ away from the source is $2-20 \mathrm{~Hz}$, which corresponds to the combination of high-frequency pressure pulse signal and low-frequency bubble pulse (Mayne and Quay 1971; Dragoset 2000). The dominating frequency drops dramatically to $2-6.5 \mathrm{~Hz}$ at stations with epicentral distances of $1.4 \mathrm{~km}$ and above. The low-frequency signal $\sim 4 \mathrm{~Hz}$ corresponds to the bubble oscillation, ${ }^{1}$ which will be mainly discussed hereafter. From above, we can see that the dominant frequency of far-field airgun signals fall into the optimal frequency response range of current permanent seismic stations, which provides a marvelous opportunity for us to utilize the existing permanent seismic stations to investigate airgun signals (Chen et al. 2008).

In order to investigate the quality and repeatability of airgun signals, we measured the $\mathrm{CC}$, average amplitudes, and signal to noise ratio (SNR) of airgun signals registered by seismic stations at different offsets (Fig. 3) from 10 individual shots under same working conditions as in Fig. 2. The amplitudes of airgun signals and ambient noise are defined as the standard deviation over a time window around the main arrival and $2 \mathrm{~s}$ before the shot time (shaded areas in Fig. 2), separately. The SNR is defined as the amplitude ratio (in $\mathrm{dB}$ ) of signal and ambient noise. The CC are calculated by correlating seismic records within signal window from individual shots with the stack of 10 shots at each station. From Fig. 3, we can see that the $\mathrm{CC}$ of airgun signals recorded by seismometers 1.4 and $7.0 \mathrm{~km}$ away are all above 0.99 . Then, they decrease from 0.99 to 0.75 with the epicentral distance increase from 7.0

\footnotetext{
${ }^{1}$ Bolt Technology Corporation, Suggestions for use of $4 \times 2,000$ cubic inch air guns in an excavation.
} 

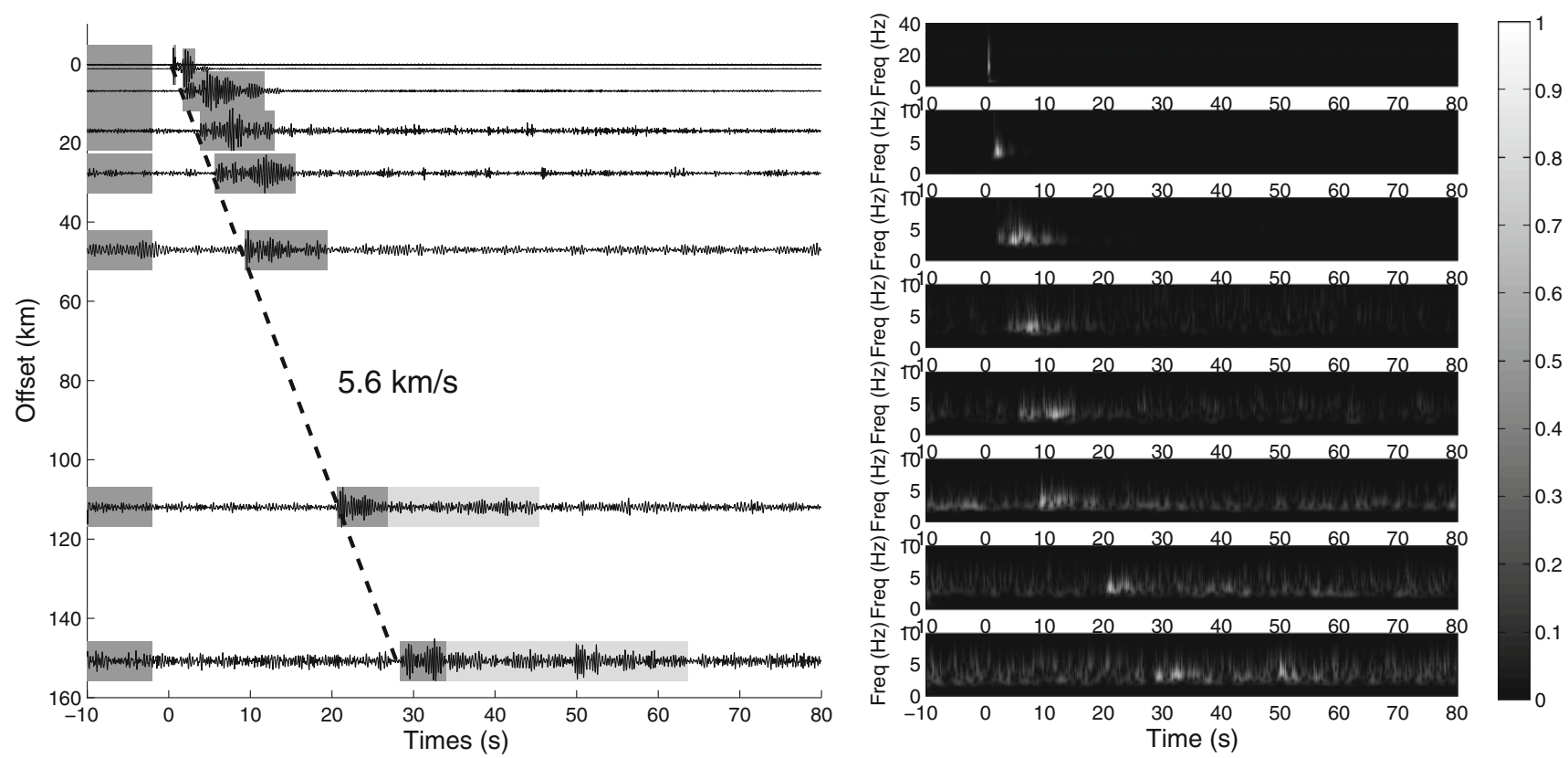

Fig. 2 Vertical component airgun signals recorded by seismometers at different offsets (from top to bottom the offsets are $50 \mathrm{~m}, 1.4 \mathrm{~km}$, $7.0 \mathrm{~km}, 17.0 \mathrm{~km}, 27.7 \mathrm{~km}, 47.0 \mathrm{~km}, 112.0 \mathrm{~km}$, and $151.0 \mathrm{~km}$, respectively; the shaded area refer to the time window for the computation of SNR.)

to $47.0 \mathrm{~km}$, and then vary slowly. The variation of SNR is similar to the variation of CC.

\section{The influence of excitation parameters on far-field airgun signals}

There are many factors that can influence airgun signals generated by large volume airguns in a water reservoir, such as airgun volume, firing pressure, airgun towing depth, water level, geometry of the water reservoir, and elastic properties of surrounding material (Vaage et al. 1983; Dragoset 2000). In this paper, we analyzed the effects of firing pressure, airgun towing depth, and water level of the reservoir. The commonly used parameters to characterize the airgun signals are the amplitude and dominant frequency of airgun signals. Moreover, the repeatability of source is of key importance in subsurface monitoring, so we also take the $\mathrm{CC}$ into consideration.

\subsection{The influence of firing pressure on far-field airgun signals}

It has long been recognized that the firing pressure has dominating effects on the seismic signal from airgun while shot off shore (Johnston 1980). So we first investigated the influences of firing pressure on the amplitudes of far-field airgun signals. Experiments were carried out by firing guns at different pressures, while keeping other factors intact. During the experiments, the water level and airgun towing depth were fixed at 12.5 and $10 \mathrm{~m}$, respectively. We adopted the same preprocess method and definition of amplitude as mentioned in Sect. 3. Figure 4 shows the variation of the amplitudes $(A)$ of airgun signals with firing pressures $(P)$. Results from previous oceanic experiments indicate that the amplitudes are exponentially proportion to the pressures $A \propto P$ (Giles and Johnston 1973; Dragoset 2000), $A \propto P^{0.551}$ (Johnston 1980) or $A \propto P^{3 / 4}$ (Vaage et al. 1983). Therefore, in this study, we use the function $A=k P^{x}$ to fit our data. From Fig. 4, we can see that the exponential indices $x$ are very close to 1 for all the seismic stations which indicate the amplitudes of far-field airgun signals recorded by seismometers on land are almost linearly proportional to firing pressures.

We compared the power spectral densities (PSD) of the low-frequency $(2-6.5 \mathrm{~Hz})$ bubble pulses to investigate the frequency contents change associated with the firing pressures change. Vertical component seismic signals from different firing pressures and corresponding PSD recorded at epicentral distance of $1.4 \mathrm{~km}$ are shown in Fig. 5. The general pattern of frequency contents observed in oceanic airgun experiments, is composed of bubble frequency and its integer harmonics (Duncan and Mccauley 2000). The bubble frequency in our experiments is estimated $\sim 3.4 \mathrm{~Hz}$. However, it can be indicated from Fig. 5 that besides bubble frequency and its integer harmonics, there are some large amplitude signals lying in $5-6 \mathrm{~Hz}$. We speculate these signals as complicated interactions between limited water body and/or the shore because they are not observed at some stations with similar distance but different azimuths (not shown here), which need to be studied 

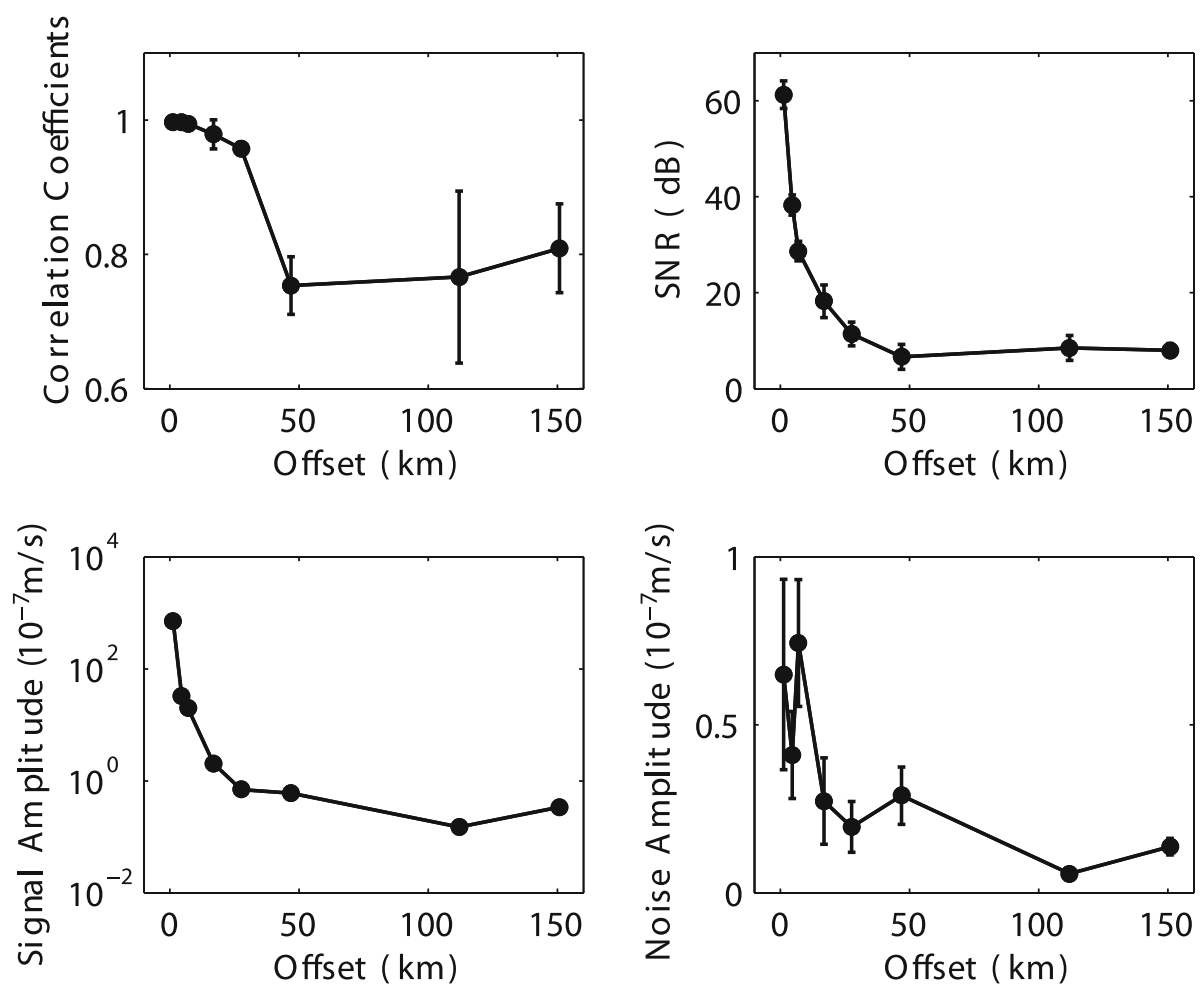

Fig. 3 The variation of correlation coefficients, signal to noise ratio, amplitude of airgun signals, and amplitude of ambient noise with offsets
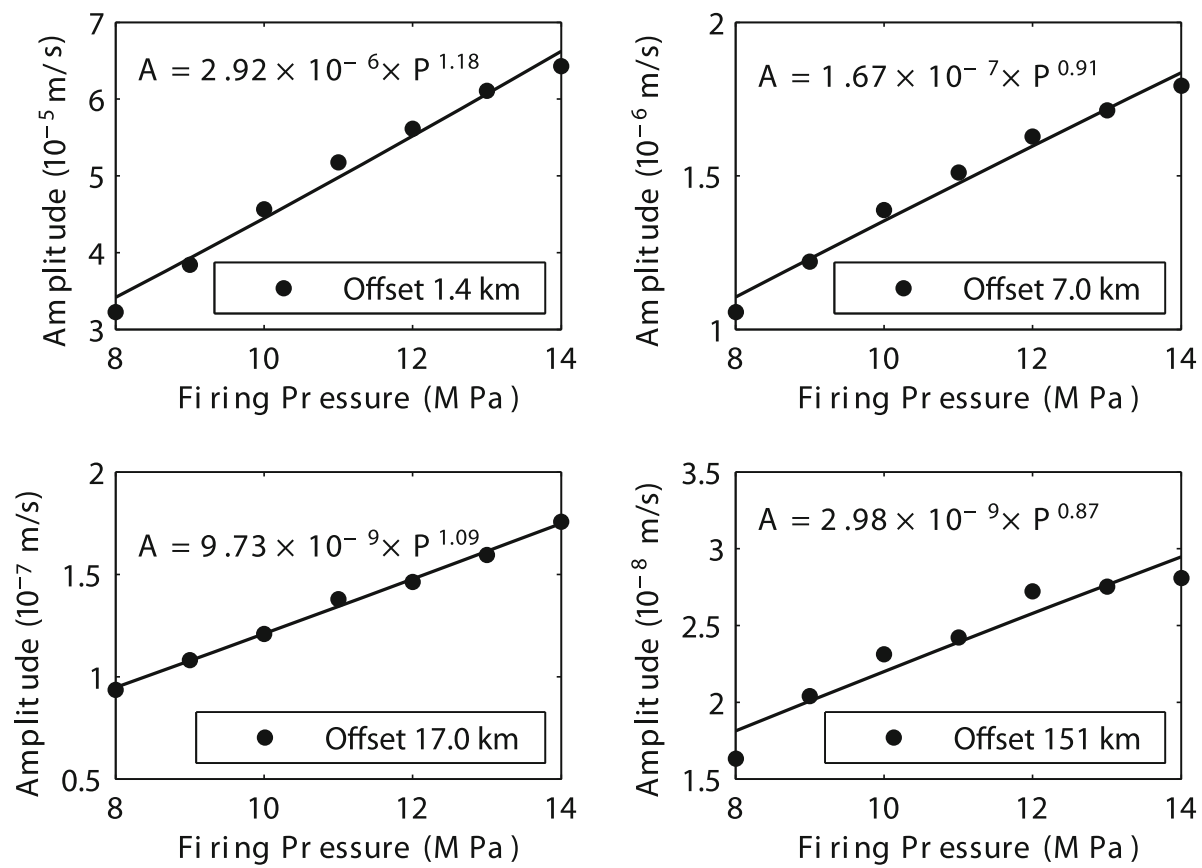

Fig. 4 The variation of the amplitudes of airgun signals with firing pressures (vertical component)

further. It can also be indicated from Fig. 5 that the peak frequency of the signal shifts a little lower with the increase of pressure. Previous studies of airguns shot in the oceans show that the bubble period is proportional to the firing pressure as $T \propto P^{1 / 3}$ (Vaage et al. 1983; Dragoset 2000; Johnston 1980). So the lower the firing pressure, the shorter the bubble period $(T)$ and the more the high-frequency energy content of airgun signals. 
(a)

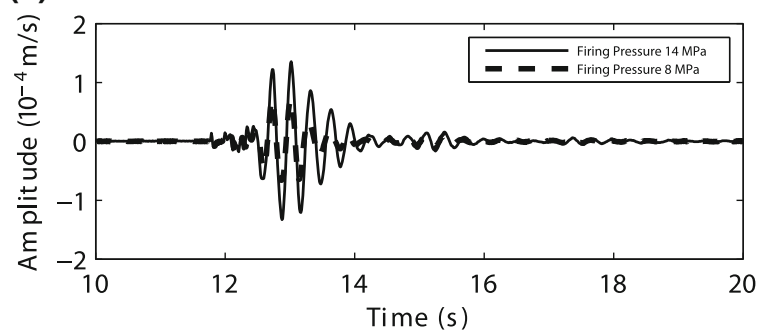

(b)

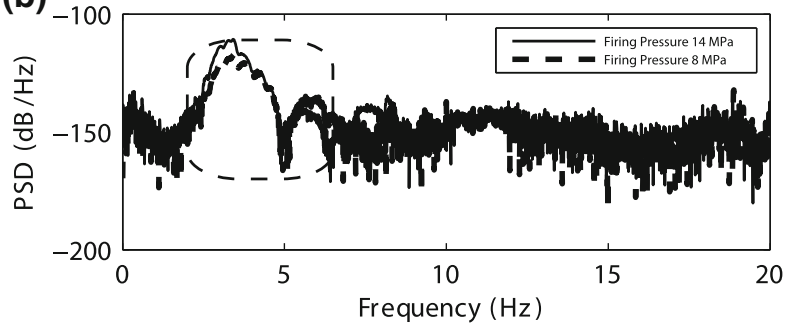

(c)

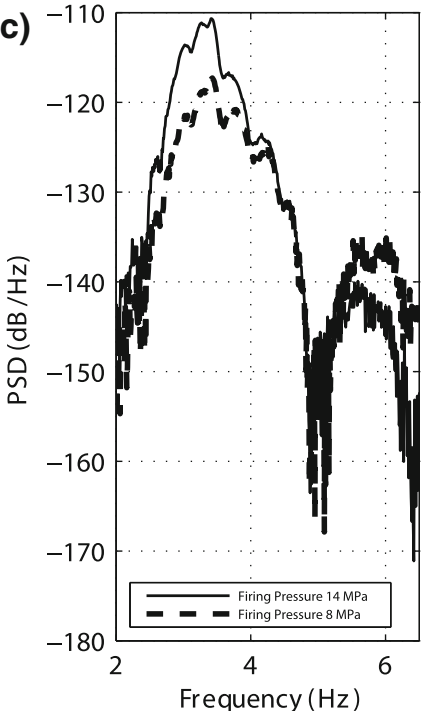

Fig. 5 The airgun signals generated under firing pressure 8 and $14 \mathrm{MPa}$ (a) and their PSD (b, c) (vertical component, offset $1.4 \mathrm{~km}$ )

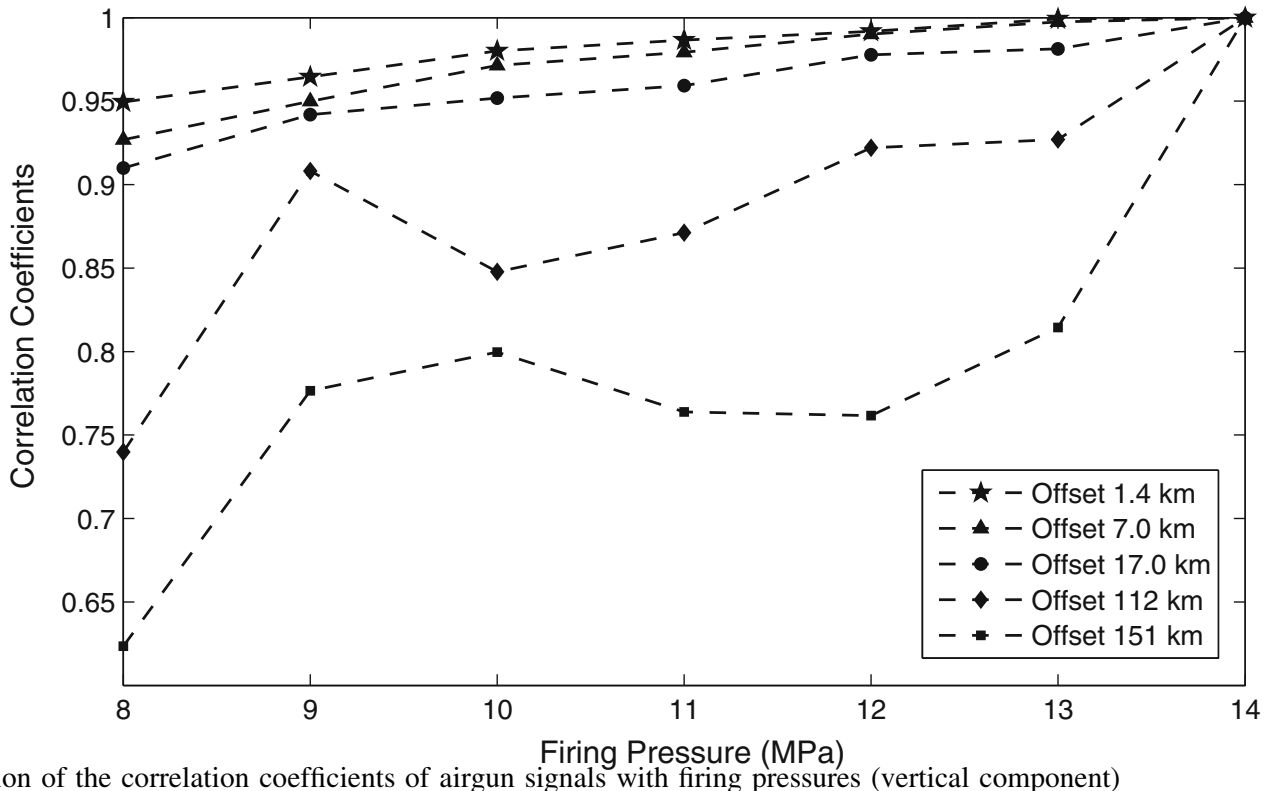

Fig. 6 The variation of the correlation coefficients of airgun signals with firing pressures (vertical component)

Waveforms generated at different pressures show clear dissimilarity (Fig. 5). We calculated the cross-CC between signal from $14 \mathrm{MPa}$ firing pressure with signals from other pressures (Fig. 6). The smaller the pressure difference, the higher the similarity is (Fig. 6). Also from Fig. 6, we can see that the effects of firing pressure on the waveform similarity increase with distance.

4.2 The influence of airgun towing depth on far-field airgun signals

The towing depth of airgun source determines the distance between source and upper and lower boundaries, which may affect the seismic signal. To investigate these effects, experiments were carried out by shooting guns at different depths (Table 1). For the safety of the equipment, experiments were carried out on day time under a moderate fire pressure $(11 \mathrm{MPa})$. And the water level of the reservoir kept constant at $12.5 \mathrm{~m}$ during these experiments.

The waveform amplitudes from two stations with high SNR are shown in Fig. 7 as functions of towing depth. From Fig. 7, we can see that in comparison with the firing pressure induced amplitude change, the towing depth shows negligible effects on signal amplitudes. This is consistent with previous results from airguns experiments in the oceans, where the amplitudes of airgun signals were 

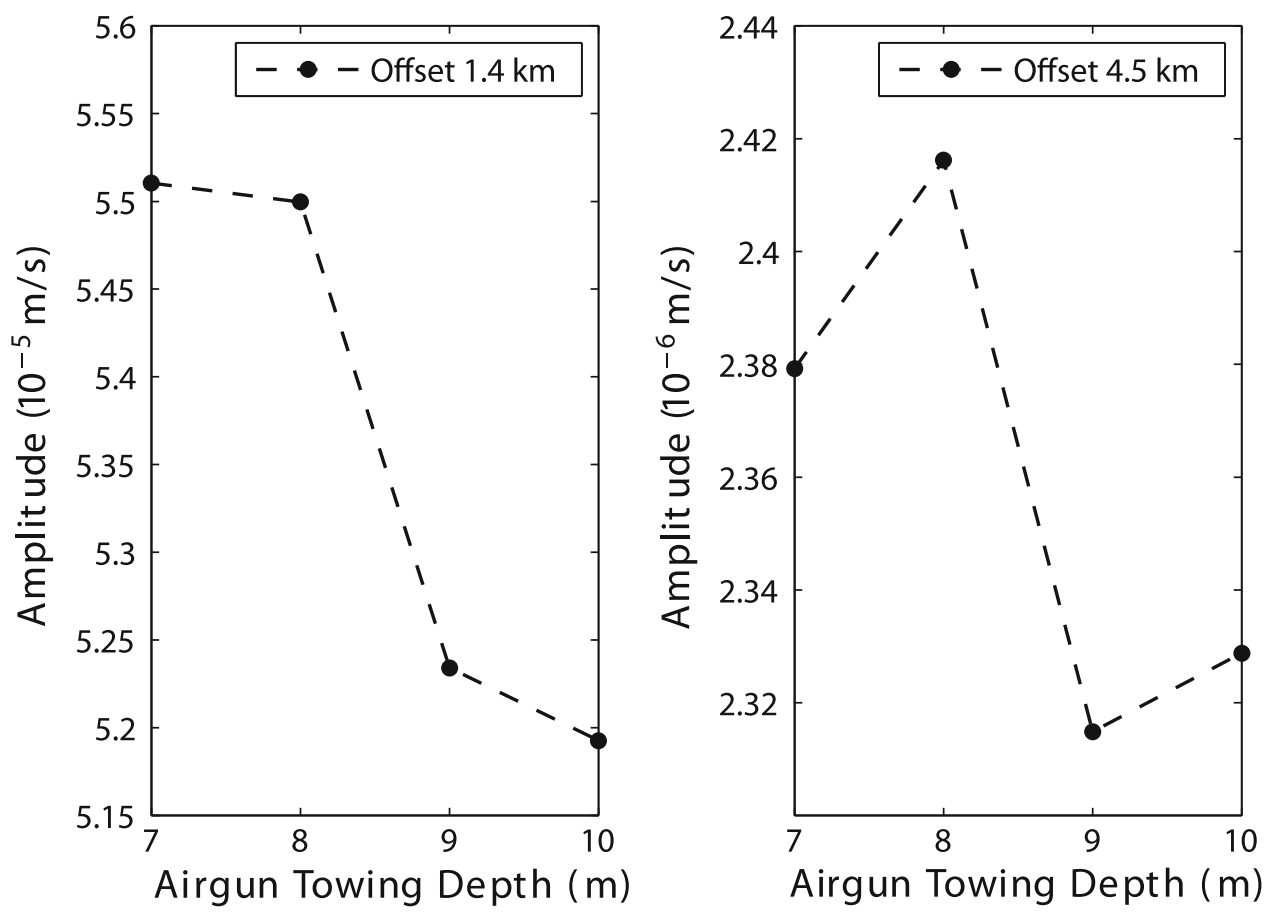

Fig. 7 The variation of amplitudes of airgun signals with airgun towing depths (vertical component)

(a)

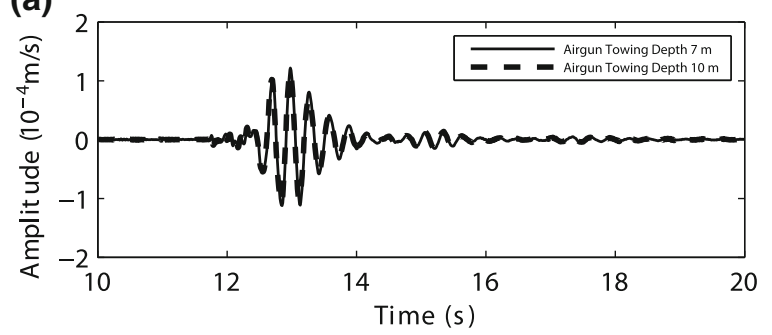

(b)

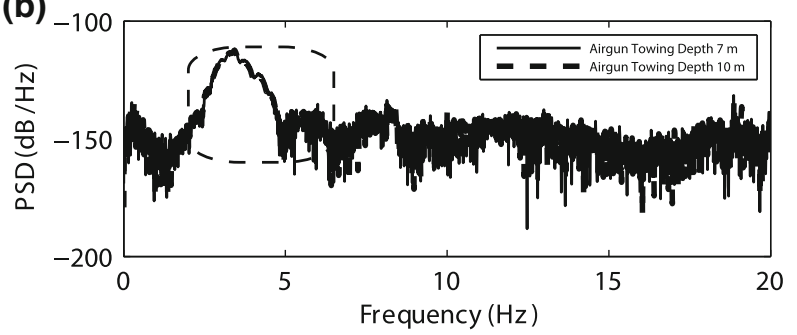

(c)

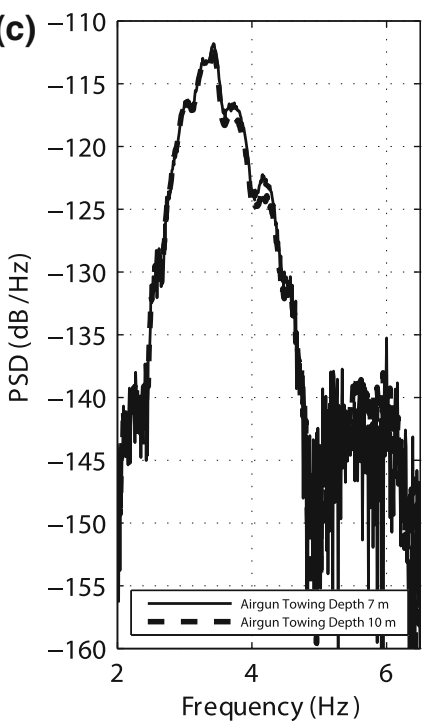

Fig. 8 The airgun signals generated at 10 and $7 \mathrm{~m}$ airgun towing depth (a) and their PSD (b, c) (vertical component, offset $1.4 \mathrm{~km})$

found independent of airgun towing depth, when the spherical divergence was corrected (Vaage et al. 1983; Mayne and Quay 1971).

The waveforms recorded at $1.4 \mathrm{~km}$ under different excitation depths are further compared in Fig. 8. Two waveforms generated under 10 and $7 \mathrm{~m}$ towing depth and their spectral contents are almost identical, except the dominating frequency of $7 \mathrm{~m}$ excitation is a little bit lower than that of $10 \mathrm{~m}$ excitation. Previous studies of airgun signals shot in the oceans show the bubble period is inversely related to the depth (Vaage et al. 1983; Dragoset 2000). So the lower the airgun towing depth, the longer/ lower the bubble period/frequency of airgun signals.

Figure 9 shows the variation of the CC of the airgun signals with airgun towing depths. The airgun signal generated at $10 \mathrm{~m}$ airgun towing depth was selected as the 


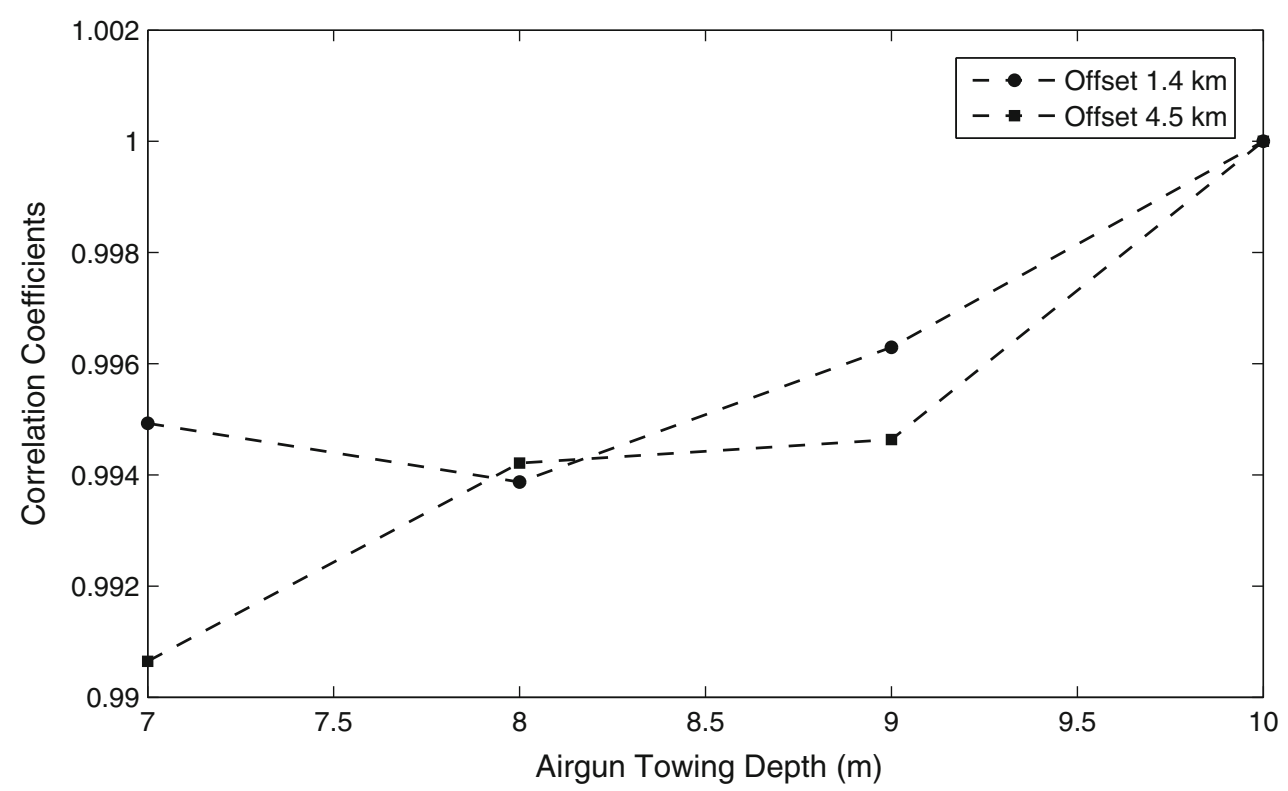

Fig. 9 The variation of the correlation coefficients of airgun signals with airgun towing depths (vertical component)

reference airgun signal. From Fig. 9, we can see that the $\mathrm{CC}$ of airgun signals also change little with airgun towing depths as what can be intuitively drawn from Fig. 8 .

\subsection{The influence of water level on far-field airgun signals}

Different from previously discussed controllable airgun working conditions, the water level in reservoir may change inevitably due to precipitation and water consumption. The water levels of first and second experiments are the same $(17.7 \mathrm{~m})$, and it decrease to $12.5 \mathrm{~m}$ during the experiments 3-5 and $10.7 \mathrm{~m}$ for experiment 6 , respectively. So, we only analyzed airgun signals collected from first, third, and sixth experiments which have distinctly different water levels (17.7, 12.5 , and $10.7 \mathrm{~m}$ ). The airgun source were fired $15 \mathrm{MPa}$ firing pressure for all three experiments. And the guns were towed 12 and $10 \mathrm{~m}$ under the water surface for experiment 1 and last two experiments, respectively. According to our above-mentioned results, towing depth plays a minor role in affecting the seismic signal. So we would like to argue that the differences of these experiments are caused by the changes of the water level of the reservoir.

The amplitudes of vertical seismic signal recorded by a station with epicentral distance $4.9 \mathrm{~km}$ are shown in Fig. 10. From Fig. 10, we can see that the amplitudes of airgun signals are almost linearly proportional to the water levels. This is because the amplitudes of the airgun signals are proportional to the radius of water surface in the reservoir (see the next section) and the wall of the water reservoir is outward-inclined. So the higher the water level is the larger the radius of water surface, and the larger the amplitudes of the airgun signals will be. The seismic waveforms generated at water level of 17.7 and $10.7 \mathrm{~m}$ and their PSD corresponding to Fig. 10 are shown in Fig. 11. Figure 12 shows the variation of the $\mathrm{CC}$ of airgun signals with water levels of the reservoir. The airgun signal generated at $17.7 \mathrm{~m}$ was selected as the reference signal. The change of water level plays an important role in waveform amplitude and frequency contents changing (Figs. 10, 11, 12) which may affect the long-term subsurface monitoring.

\section{Interpretations and discussion}

\subsection{Theoretical model for airgun source excited} in a limited water body

In this paper, three different factors influencing airgun signals are investigated. The influences of first two parameters firing pressure and towing depth were relatively well documented. While the water depth affect is a new problem faced during carrying out airgun experiment in a land water reservoir. In this section, we propose a simplified model to study the effects of different factors on farfield airgun signals. We made following simplifications: 1 . The airgun array is simplified as a large volume airgun and further as single force point source, this is an acceptable simplification since we are concentrating on far-field signals (Luo et al. 2007); 2. The airgun bubble behaves approximately as a spherical bubble of an ideal gas in an infinite volume of incompressible water (Johnson 1994); 3. The far-field signal is proportional to total force acting on the water bottom; 4. For clarity the water bottom is simplified as a flat boundary and water body cylindric. The idea model is shown in Fig. 13. 


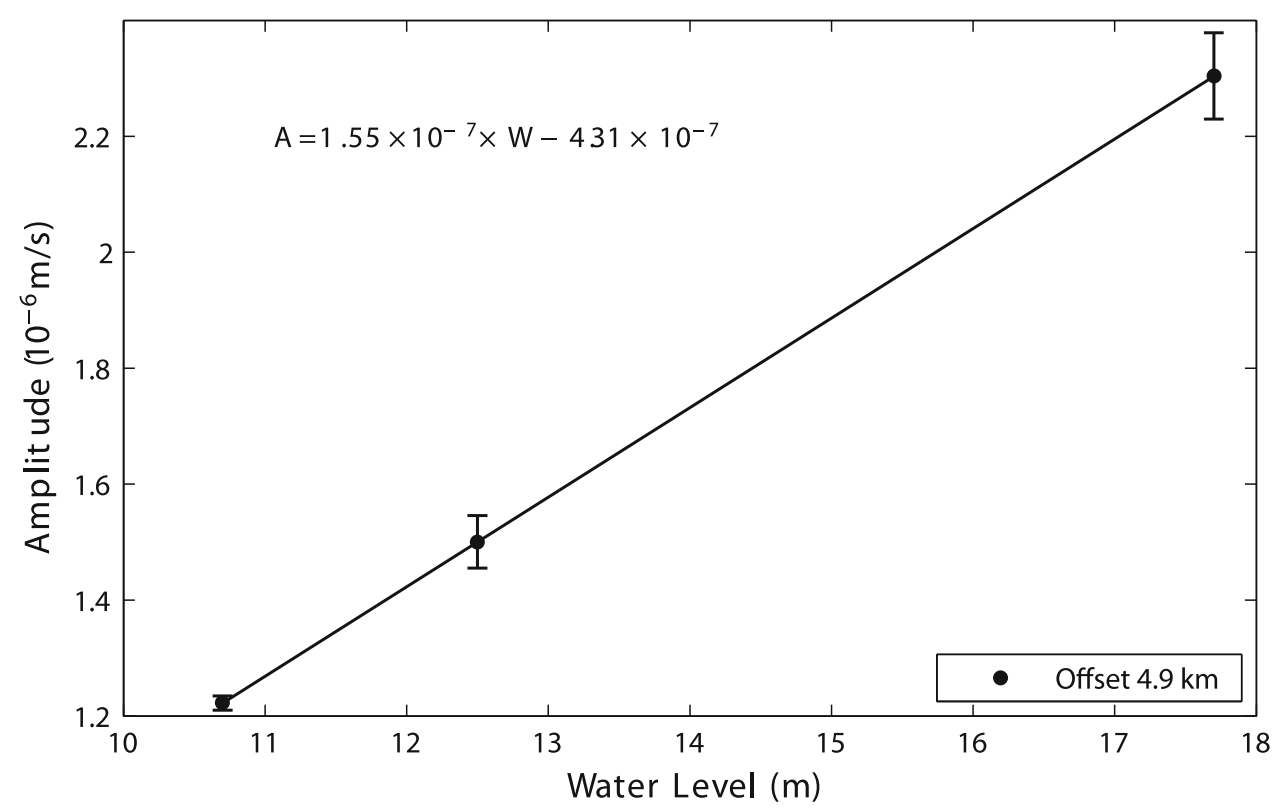

Fig. 10 The variation of the amplitudes of airgun signals with water levels (vertical component, offset $4.9 \mathrm{~km}$ )
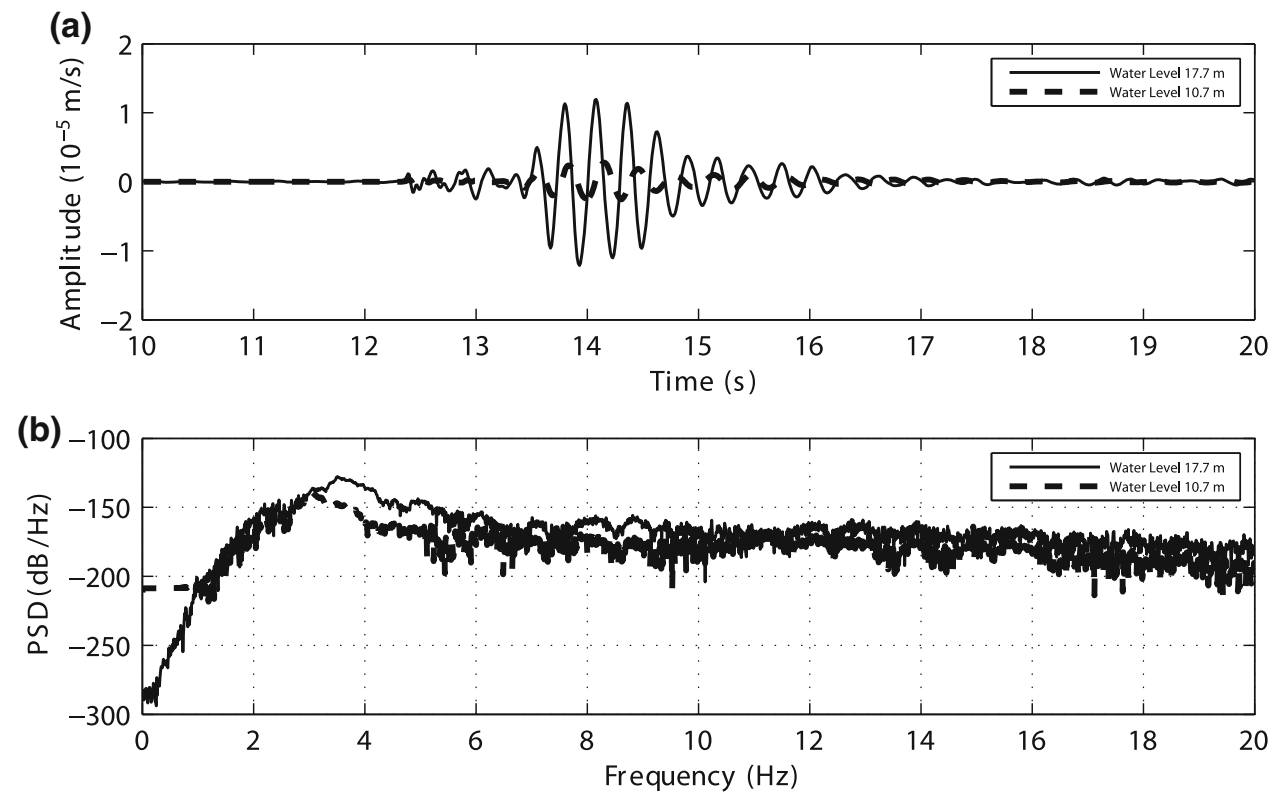

Fig. 11 The airgun signals generated at water level of 17.7 and $10.7 \mathrm{~m}$ (a) and their PSD (b) (vertical component, offset $4.9 \mathrm{~km}$ )

According to momentum equation and continuity equation, the total force acting on the cylindric water bottom can be written as (Chen et al. 2014)

$F=2 \pi a L\left(p_{a}+\frac{\rho_{\mathrm{w}} u^{2}}{2}\right)$,

where $a$ is the bubble radius, $u$ is the particle velocity at the bubble wall (the derivative of bubble radius), $L$ is the radius of the water surface in the reservoir, $p_{a}$ is the absolute air pressure inside the bubble, $\rho_{\mathrm{w}}$ is the density of water. Because the total force at the bottom of the water reservoir $(F)$ is maximal at the initial state (Chen et al. 2014), we only consider the total force at the initial state $\left(F_{1}\right)$

$F_{1}=2 \pi a_{1} L\left(p_{a 1}+\frac{\rho_{\mathrm{w}} u_{1}^{2}}{2}\right)$,

where variables with suffix 1 are their values at initial state. The bubble radius at the initial state can be evaluated by $a_{1}=\left(\frac{3 V_{1}}{4 \pi}\right)^{\frac{1}{3}}$, where $V_{1}$ is the volume of the airgun air 


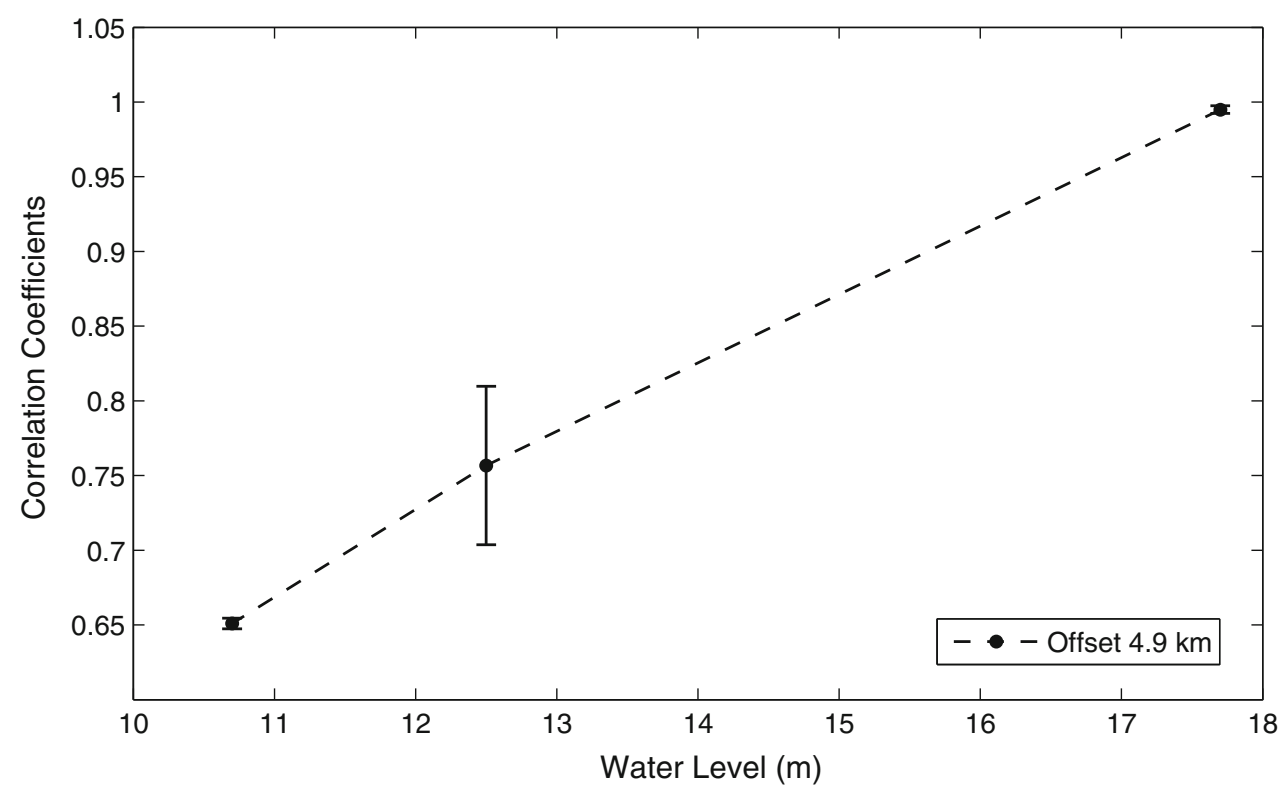

Fig. 12 The variation of the correlation coefficients of airgun signals with water levels (vertical component, offset $4.9 \mathrm{~km}$ )

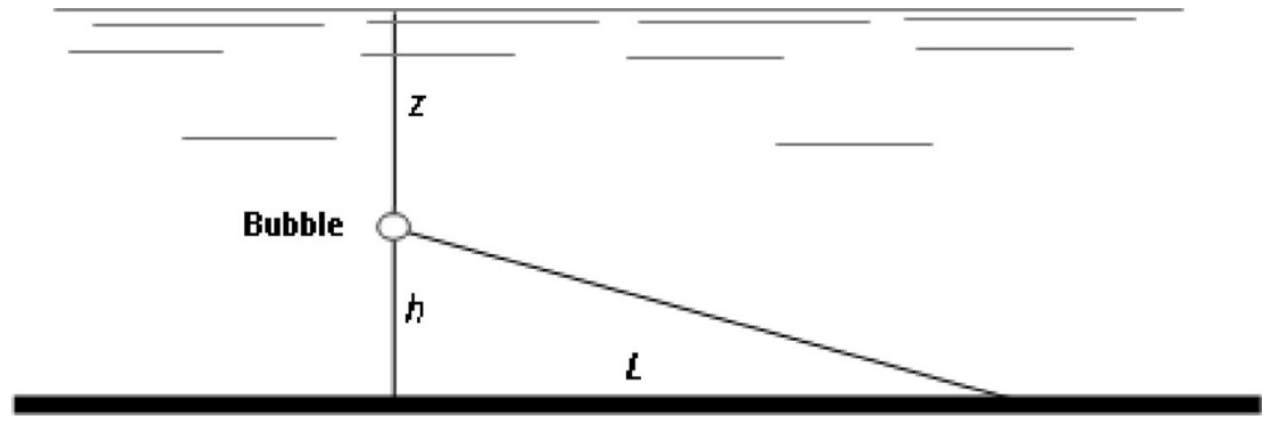

Fig. 13 Diagram of airgun excitated in a water reservoir. Here $z, h$, and $L$ are towing depth, distance to water bottom, and the radius of the water bottom, respectively

chamber. The initial particle velocity on the bubble wall is zero, i.e., $u_{1}=0$. The initial air pressure inside the bubble $p_{a 1}$ is equivalent to the firing pressure. Then, the total force at the initial moment can be written as

$F_{1}=2 \pi L\left(\frac{3 V_{1}}{4 \pi}\right)^{\frac{1}{3}} p_{a 1}$

It can be inferred from Eq. (3) that the total force at the initial moment is proportionally related to the radius of water surface, airgun volume to the power of $1 / 3$, and the firing pressure, but not related to the towing depth. These deductions coincide with our experimental results.

The main frequency of airgun signals is determined by the period of air bubble. The period of air bubble is given by (Johnson 1994)

$T=2 \pi a_{0} \sqrt{\frac{\rho_{\mathrm{w}}}{3 \gamma \rho_{0}}}$, where $a_{0}$ is the equilibrium radius, $\rho_{0}$ is the equilibrium pressure, $\gamma$ is the thermodynamic parameter (about 1.13 based on fitting empirical airgun data).

The equilibrium pressure $\left(p_{0}\right)$ is given by

$p_{0}=p_{\mathrm{n}}+p_{\mathrm{c}}=\rho_{\mathrm{w}} g z+p_{\mathrm{c}}$,

where $p_{\mathrm{c}}$ is the atmospheric pressure, $p_{\mathrm{n}}$ is the hydrostatic pressure, $g$ is the gravitational acceleration, $z$ is the airgun towing depth.

The equilibrium radius $\left(a_{0}\right)$ is given by (Johnson 1994; Ziolkowski 1970)

$a_{0}=a_{1}\left(\frac{p_{a 1}}{p_{0}}\right)^{\frac{1}{3 \gamma}}=a_{1}\left(\frac{p_{a 1}}{\rho_{\mathrm{w}} g z+p_{\mathrm{c}}}\right)^{\frac{1}{3 \gamma}}$.

Substitute Eqs. (5) and (6) into Eq. (4), the period of the air bubble can be written as 


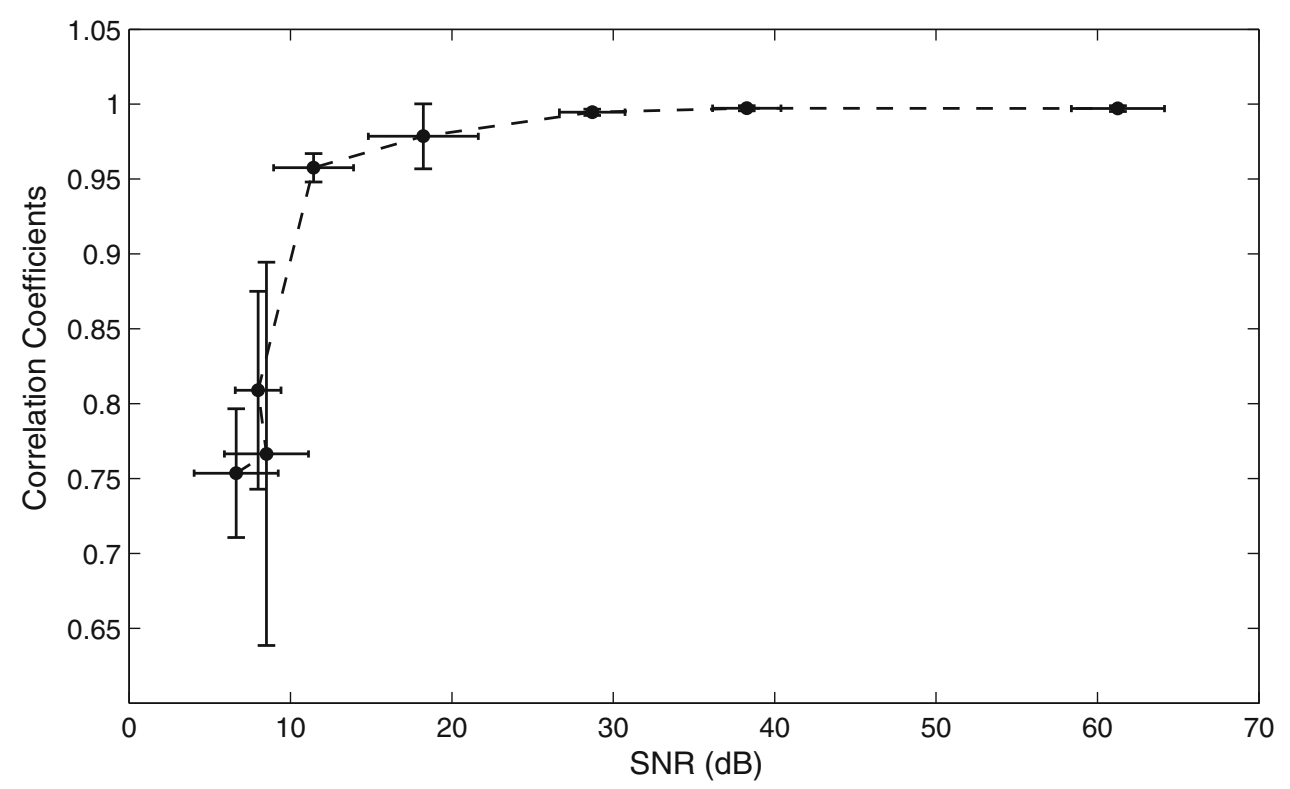

Fig. 14 The relations between the correlation coefficients and the SNR of the airgun signals with the same excitation parameters

$$
\begin{aligned}
T & =2 \pi a_{1}\left(\frac{p_{a 1}}{p_{\mathrm{c}}+\rho_{\mathrm{w}} g z}\right)^{\frac{1}{3 \gamma}} \sqrt{\frac{\rho_{\mathrm{w}}}{3 \gamma\left(\rho_{\mathrm{w}} g z+p_{\mathrm{c}}\right)}} \\
& =\frac{2 \pi}{\sqrt{3 \gamma g}}\left(\frac{3 V_{1}}{4 \pi}\right)^{\frac{1}{3}}\left(\frac{p_{a 1}}{\rho_{\mathrm{w}} g}\right)^{\frac{1}{3 \gamma}}\left(\frac{1}{\left(\frac{p_{\mathrm{c}}}{\rho_{\mathrm{w}} g}+z\right)^{\left(\frac{1}{3 \gamma}+\frac{1}{2}\right)}}\right) .
\end{aligned}
$$

Given $\quad p_{\mathrm{c}}=1.013 \times 10^{5} \mathrm{~Pa}, \quad g=9.8 \mathrm{~m} / \mathrm{s}^{2}, \quad \rho_{\mathrm{w}}=$ $1,000 \mathrm{~kg} / \mathrm{m}^{3}, \gamma=1.13 \approx 1$. The period of the air bubble can be approximately written as

$T \approx \frac{2 \pi}{\sqrt{29}}\left(\frac{3 V_{1}}{4 \pi}\right)^{\frac{1}{3}}\left(\frac{\rho_{a 1}}{9800}\right)^{\frac{1}{3}} \frac{1}{(10+z)^{5 / 6}}$.

The International System of Units (SI) is used for other quantities. From Eq. (8), we can see that the period of the air bubble is proportional to the firing pressure to the power of $1 / 3$. The period of the air bubble is proportional to the airgun volume to the power of $1 / 3$ and is inversely proportional to the airgun towing depth $\left(\propto \frac{1}{(10+z)^{5 / 6}}\right)$. These coincide with our experiments too.

\subsection{The cause of dissimilarity}

High repeatability is one of the most important features of airgun source excited in water. Taking the advantage of high source repeatability, we can detect the signal at longer distance by stacking individual shot (Lin et al. 2008), and monitor subtle material changes (Reasenberg and Aki 1974; Liu et al. 1983). Our results show seismic signal from airgun array is of high similarity at short epicentral distance, while the $\mathrm{CC}$ decrease to lower than 0.8 at stations further than $50 \mathrm{~km}$. Two main factors may decrease the similarity are the drop of source repeatability and the increase of noncorrelated noise relative to signal. The source repeatability is ensured by high CC at stations with short offset (Fig. 3). The reduction of SNR is the most like cause of dissimilarity. The relationship between SNR and CC is shown in Fig. 14. $\mathrm{CC}$ appears to monotonously increasing with SNR. To quantitatively describe the dependency of CC and SNR, we calculated their rank $\mathrm{CC}$. The rank $\mathrm{CC}$ is estimated to be 0.95, which suggests that the $\mathrm{CC}$ and SNR are strongly correlated. It means to have high $\mathrm{CC}$ we need high SNR either by increase the source power or by stacking more records from repeatable source (Niu et al. 2008).

\section{Conclusions}

Large volume airgun array in a water reservoir is now being used for seismic exploration and subsurface monitoring with a limited knowledge about the source signature. Based on seismic data from several field experiments at Binchuan TSS, we investigated the influencing factors of far-field airgun signals. Our results suggest that firing pressure and water level have prominent effects on seismic signal generated by airgun source, while the effect from towing depth is relatively negligible. A simplified model was also proposed which explain our data well. Excited in a water body with limited volume, airgun signal may have complicated interactions with shore, water surface, and the bottom of the reservoir, which is a question to be studied further. 
Acknowledgements This study is supported by the China National Special Fund for Earthquake Scientific Research in Public Interest (No. 201208004), National Natural Science Foundation of China (Nos. 41222029 and 41174040), Basic Research and Development Operations Special Fund of the Institute of Geophysics, China Earthquake Administration (No. DQJB10A01), and Foundation for Young Scientists of Yunnan Earthquake Administration (No. 201407)

\section{References}

Chen L, Ding Y, Qiao J (2014) Advices on the construction of Xinjiang Transmitting Seismic Station (in preparation)

Chen Y, Liu L, Ge H, Liu B, Qiu X (2008) Using an airgun array in a land reservoir as the seismic source for seismotectonic studies in northern China: experiments and preliminary results. Geophys Prospect 56:601-612

Choukroune P (1989) The Ecors Pyrenean deep seismic profile reflection data and the overall structure of an orogenic belt. Tectonics 8:23-39

Cox E, Pearson A, Blake JR, Otto SR (2004) Comparison of methods for modelling the behaviour of bubbles produced by marine seismic airguns. Geophys Prospect 52:451-477

Dragoset B (2000) Introduction to air guns and air-gun arrays. Lead Edge 19:892-897

Duncan A, Mccauley R (2000) Characterisation of an air-gun as a sound source for acoustic propagation studies. In: Proceedings of UDT Pacific 2000, Darling Harbour, Australia, 7-9 Feb Acoustics 20005

Giles BF, Johnston RC (1973) System approach to air-gun array design. Geophys Prospect 21:77-101

Huang J, Liu X, Su Y, Wang B (2012) Imaging 3-D crustal P-wave velocity structure of western Yunnan with bulletin data. Earthq Sci 25:151-160

Johnson DT (1994) Understanding air-gun bubble behavior. Geophysics 59:1729-1734

Johnston RC (1980) Performance of 2000 and 6000 psi air guns: theory and experiment. Geophys Prospect 28:700-715

Kramer FS, Peterson RA, Walter WC (1968) Seismic energy sources 1968 handbook. In: The 38th meeting of the Society of Exploration Geophysicists

Langhammer J, Landro M (1993a) Experimental study of viscosity effects on air-gun signatures. Geophysics 58:1801-1808

Langhammer JAN, Landro M (1993b) Temperature effects on airgun signatures. Geophys Prospect 41:737-750

Leary PC, Malin PE (1982) Millisecond accurate monitoring of seismic travel times over 13- and 18-kilometer baselines. J Geophys Res 87:6919-6930

Li G, Cao M, Chen H, Ni C (2011) Modelling the signature of clustered airguns and analysis on the directivity of an airgun array. J Appl Geophys 8:92-98
Lin J, Wang B, Ge H, Tang J, Zhang X, Chen Y (2008) Study on large volume airgun source characteristics and seismic phase analysis. Chin J Geophys 51:206-212 (in Chinese with English abstract)

Lin J, Wang B, Ge H, Xu P, Chen Y (2010) Characters of large volume air-gun source excitation. Chin J Geophys 53:342-349 (in Chinese with English abstract)

Liu H, Westerlund RE, Fletcher JB (1983) Precise measurement of seismic traveltimes-investigation of variation from tidal stress in shallow crust. Geophys Res Lett 10:377-380

Liu H, Sembera ED, Westerlund RE, Fletcher JB, Reasenberg P, Agnew DC (1985) Tidal variation of seismic travel times in a Massachusetts granite quarry. Geophys Res Lett 12:243-246

Luo G, Ge H, Wang B, Hu P, Chen Y (2007) Fired models of air gun source. Earthq Res China 23:225-232 (in Chinese with English abstract)

Lutter WJ, Fuis GS, Thurber CH, Murphy J (1999) Tomographic images of the upper crust from the Los Angeles basin to the Mojave Desert, California: results from the Los Angeles Region Seismic Experiment. J Geophys Res 104:25543-25565

Matthews DH, The BIRPS Group (1990) Progress in BIRPS deep seismic reflection profiling around the British Isles. Tectonophysics 173:387-396

Mayne W, Quay R (1971) Seismic signatures of large air guns. Geophysics 36:1162-1173

Niu F, Silver PG, Daley TM, Cheng X, Majer EL (2008) Preseismic velocity changes observed from active source monitoring at the Parkfield SAFOD drill site. Nature 454:204-208

Nooteboom JJ (1978) Signature and amplitude of linear airgun arrays. Geophys Prospect 26:194-201

Okaya D, Henrys S, Stern T (2002) Double-sided onshore-offshore seismic imaging of a plate boundary: super-gathers across South Island, New Zealand. Tectonophysics 355:247-263

Qiu X, Chen Y, Zhu R, Xu H, Shi X, Ye C, Zhao M, Xia S (2007) The application of large volume airgun sources to the onshoreoffshore seismic surveys: implication from the experimental results in northern South China Sea. Chin Sci Bull 52:463-469 (in Chinese)

Reasenberg P, Aki K (1974) A precise, continuous measurement of seismic velocity for monitoring in situ stress. J Geophys Res 79:399-406

Safar MH (1976) The radiation of acoustic waves from an air-gun. Geophys Prospect 24:756-772

Schulze-Gattermann R (1972) Physical aspects of the "airpulser" as a seismic energy source. Geophys Prospect 20:155-192

Vaage S, Haugland K, Utheim T (1983) Signatures from single airguns. Geophys Prospect 31:87-97

Wang B, Ge H, Yang W, Wang W, Wang B, Wu G, Su Y (2012) Transmitting seismic station monitors fault zone at depth. Eos Trans Am Geophys Union 93:49-50

Ziolkowski A (1970) A method for calculating the output pressure waveform from an air gun. Geophys J R Astron Soc 21:137-161 